\title{
Neurofibromatosis type 1 (NF1): knowledge, experience, and reproductive decisions of affected patients and families
}

\author{
C M Benjamin, A Colley, D Donnai, H Kingston, R Harris, L Kerzin-Storrar
}

\begin{abstract}
Eighty-one subjects ( 56 affected patients and 25 parents of isolated affected cases) from 63 families with neurofibromatosis type 1 (NF1) on the North Western Regional Genetic Family Register (NWRGFR) were interviewed. Patients were interviewed either before $(n=26)$ or after $(n=55)$ genetic counselling. In the group as a whole, knowledge of the clinical features and the genetic aspects of the condition was poor (mean score 7 within the range of 0 to 18). The following factors were significantly associated with higher knowledge: (1) genetic counselling, (2) higher social class, (3) child with NF1, (4) when NF1 had influenced reproductive decisions, (5) young age at diagnosis, and (6) member of a patient support group.

The majority of the affected subjects perceived themselves to be more severely affected than by medical classification, with persons who had been diagnosed later in life, had a child with NF1, or who were concerned about the cosmetic aspects of the disease perceiving themselves to be more severely affected.
\end{abstract}

Assessment of the psychosocial effects of NF1 at different stages of life showed that $63 \%$ of affected subjects experienced difficulties at school and $48 \%$ said that the condition, particularly cosmetic aspects, caused anxiety during adolescence $(n=54)$. These difficulties may have contributed to later problems with career attainment and confidence in relationships. Seventy-seven percent of parents stated that their child was experiencing difficulties at school relating to NF1 $(\mathbf{n}=51)$.

Of the subjects at risk of having a child with NF1 and who knew about NF1 before having their family $(n=32), 45 \%$ said that it had influenced their reproductive decisions. Of 29 subjects who were still considering children, $41 \%$ wished to have prenatal diagnosis in a future pregnancy, but only three subjects stated that they would terminate an affected pregnancy. (f Med Genet 1993;30:567-74)

Neurofibromatosis type 1 (NF1) is one of the most common autosomal dominant conditions, affecting approximately 1 in 3000 persons. Over the last few years the clinical phenotype has been characterised and the variability of the condition fully recognised. The main features of the condition include café au lait patches, axillary and groin freckling, Lisch nodules, and peripheral neurofibromas. Complications can occur, including central nervous system tumours $(2 \%)$, scoliosis $(5 \%)$, plexiform neurofibromas $(32 \%)$, learning difficulties $(30 \%)$, and epilepsy $(4 \%) .{ }^{1}$ Diagnosis of the condition can often be missed as the significance of the café au lait patches may not be recognised, and often there is no family history because of the condition's high mutation rate $\left(1 \times 10^{-4}\right){ }^{2}$ The extreme variability in the phenotypic expression of the NF1 gene makes it difficult for patients to comprehend the variety of problems associated with the condition and previous studies have noted that patients often know little about the clinical and genetic aspects. ${ }^{3}$ Children of affected subjects have a $50 \%$ chance of inheriting the gene which is almost $100 \%$ penetrant by the age of 6 years. Parents of isolated cases can only be reassured that they do not carry the gene after a detailed clinical examination.

Previous studies have shown that the presence of a genetic disorder can have significant social and psychological effects on the affected subject and the extended family. In families with NF1 the shock at the time of diagnosis and the social effects owing to the cosmetic aspects of the condition have been commented on. ${ }^{4-6}$

Investigations into the molecular defect responsible for NF1 resulted in the cloning of the NF1 gene in $1990 . .^{78}$ The reproductive decision making process of couples at risk of genetic disorders has been shown to be complex and involve many factors other than the magnitude of the genetic risk and the features of the condition. In NF1 the situation is complicated by the potential variability of clinical features and the fact that for the majority of subjects it represents a cosmetic skin condition with few pathological features.

Support groups for many genetic conditions are now established. These groups provide education, information, and the opportunity to share common concerns and reduce feelings of isolation. The Neurofibromatosis Association (LINK) has been established for 12 years and provides a range of 14 leaflets describing features of both NF1 and NF2.

Given the limited information available on families' perception of NF1 and its psychosocial impact, this study sought to assess: (1) the clinical and genetic knowledge of affected subjects and unaffected parents, (2) retrospectively, the experiences of affected subjects through different life stages, (3) the use of LINK and other social support, (4) the repro- 
ductive decisions of affected persons, and (5) the likely prospective demand for prenatal diagnosis.

\section{Methods}

NF1 is one of 11 disorders at present on the NWRGFR. The register aims to extend counselling from the proband to all at risk and affected relatives, to offer annual review by clinic appointment or letter, and to provide reinforcement counselling over a number of years. Each patient with NF1 seen in the genetic counselling clinic is offered the services of the register. If a child is diagnosed as having NF1 they are placed on the register under the name of one of their parents until they are seen in the clinic as a young adult and asked if they wish to remain on the register. The study population consists of those subjects on the register seen at the NF1 clinic at St Mary's Hospital, Manchester, UK who were over the age of 18 at interview and either affected or the parent of an affected child (table 1). All subjects on the register before September 1990 were invited to take part in the study. In order to compare data from subjects who had attended the genetic clinic in the last year (counselled group $\mathrm{n}=55$ ) with those who had not yet received counselling (non-counselled group $\mathrm{n}=26$ ), some families newly referred during the study period or members of known families who had not previously been seen were interviewed before their genetic clinic appointment.

Each potential subject was contacted by letter and asked if they would be willing to participate in the study. If they agreed, a home visit or hospital appointment was arranged. When both the parents of a child with NF1 were present questions were addressed to the couple and where answers were in disagreement between the couple this was noted. The final study questionnaire contained four sections: (1) background information, (2) knowledge of clinical and (3) genetic aspects of NF1, and (4) the psychosocial aspects and experience of affected families.

The background information section included the medical severity grade for the patient or family. The grade was assigned by one of the authors (CMB) after review of the medical history of the patients and their family. The scale, grade 1 to grade 4 , is based on the criteria set out by the Baylor NF Program Study. "Grade 1: Minimal NF1. The presence of a few features, with no compromise of health or well-being. Grade 2: Mild NF1. The presence of enough stigmata to make the disease obvious and a source of concern but without significant compromise of health; for example, facial café au lait or a modest number of cutaneous or deep neurofibromas. Grade 3: Moderate NF1. The presence of NF1 features associated with unequivocal compromise of health and wellbeing, but ones that can be reasonably well managed, are not intractable, or will not invariably lead to a shortened life span. Grade 4: Severe NF1. The presence of serious compromise that is intractable, is managed or treated only with difficulty, or, at least statistically associated with a shortened life span."

In the psychosocial section a four point Likert scale was used to assess for each question how a particular aspect of NF1 had affected the family, and to what extent this had caused them concern. In this section the questions start by addressing the problems the patient may have faced in childhood before continuing to the problems faced now and potentially in the future. Throughout this section additional comments made by the interviewees were noted.

To assess how subjects perceive their social support system the shortened version of the 27 item Social Support Questionnaire (SSQ) was used, the SSQ-6. ${ }^{10}$ The SSQ-6 questionnaire is a self assessment tool and consists of 12 questions. Descriptions of six sets of circumstances where support may be used were given and the subjects were asked to list the people whom they could rely on in each situation (SSQ-N) and then to indicate how satisfied they are with this support on a six point scale (SSQ-S). In the cases where both parents of a child with NF1 were present at the interview then the SSQ- 6 was completed by the mother in isolation.

\section{Results}

All of the 81 subjects on the NWRGFR before September 1990 were invited to participate and 70 were interviewed. In two cases the affected child had recently been adopted and a letter was not sent, in seven cases the subjects refused participation, and one adult was out of the country during the period of the study. In one case no reply was received to the initial letter. Of the seven subjects who refused, five were male and two female, and none had children. Of those subjects invited to participate after September 1990, all agreed to be interviewed. The uptake rate for the group as a whole was $86 \%$ (table 1 ).

The age range of the 81 persons interviewed was 18 to 66 years (mean 36.8 years, SD 11.3 years). The study group consisted of 60 females and 21 males. The 81 subjects inter-

Table 1 Ascertainment of study cohort.

\begin{tabular}{|c|c|c|c|c|c|c|c|}
\hline & \multicolumn{6}{|c|}{ Subjects on register } & \multirow{3}{*}{$\begin{array}{c}\text { Total } \\
\text { interviewed } \\
(a+b)\end{array}$} \\
\hline & \multicolumn{3}{|c|}{ Before Sept 90} & \multicolumn{3}{|c|}{ Sept 90-Dec 91} & \\
\hline & Total & Invited & $\begin{array}{l}\text { Interviewed } \\
\text { (a) }\end{array}$ & Total & Invited & $\begin{array}{l}\text { Interviewed } \\
\text { (b) }\end{array}$ & \\
\hline $\begin{array}{l}\text { Affected adults } \\
\text { Unaffected parent }\end{array}$ & $\begin{array}{l}57 \\
24\end{array}$ & $\begin{array}{l}57 \\
24\end{array}$ & $\begin{array}{l}48 \\
22\end{array}$ & $\begin{array}{l}20 \\
10\end{array}$ & $\begin{array}{l}8 \\
3\end{array}$ & $\begin{array}{l}8 \\
3\end{array}$ & $\begin{array}{l}56 \\
25\end{array}$ \\
\hline Total & 81 & 81 & 70 & 30 & 11 & 11 & 81 \\
\hline
\end{tabular}


Table 2 Signs and symptoms mentioned as being part of NF1.

\begin{tabular}{lcc}
\hline Feature & \multicolumn{2}{c}{$\begin{array}{c}\text { Subjects mentioning } \\
\text { feature }(\mathrm{n}=81)\end{array}$} \\
\cline { 2 - 3 } & No & $\%$ \\
\hline Café au lait patches/brown marks & 72 & 89 \\
Lumps on/under skin & 69 & 85 \\
Bone problems & 25 & 31 \\
Learning difficulties & 24 & 30 \\
Eye problems & 22 & 27 \\
Cancers & 16 & 20 \\
Freckling under arms/groin & 8 & 10 \\
Large head & 6 & 7 \\
Others & 36 & 44 \\
\hline
\end{tabular}

Table 3 Number of subjects naming the following as main source of information or support.

\begin{tabular}{lccc}
\hline & $\begin{array}{c}\text { Concerning } \\
\text { the clinical } \\
\text { features of } \\
\text { NF1 }\end{array}$ & $\begin{array}{c}\text { Concerning } \\
\text { the inheritance } \\
\text { of NF1 }\end{array}$ & $\begin{array}{c}\text { If worried } \\
\text { about } \\
\text { NF1 }\end{array}$ \\
\hline $\begin{array}{l}\text { Clinical geneticist } \\
\text { Other hospital }\end{array}$ & 44 & 51 & 29 \\
specialist & 12 & 6 & 14 \\
GP & 1 & 0 & 34 \\
Family member & 1 & 2 & 0 \\
LINK & 9 & 5 & 0 \\
Nobody & 13 & 17 & 3 \\
Other & 1 & 0 & 1 \\
Total & 81 & 81 & 81 \\
\hline
\end{tabular}

viewed were from 63 families, 28 of which had an isolated case and 35 a family history. The socioeconomic status of the study group did not differ significantly $(p=0 \cdot 2-0.5)$ from the expected frequencies for the general population. Of affected subjects interviewed, 20 were male and 36 female $(n=56)$. These subjects showed the following grades of severity: 32 $(57 \%)$ grade $1,14(25 \%)$ grade $2,10(18 \%)$ grade 3 , and no grade 4 classifications $(n=56)$. The mean severity grade for this group is therefore $1 \cdot 61$. Nineteen persons $(24 \%)$ had never had genetic counselling, $55(68 \%)$ had received counselling within the last year, and seven $(9 \%$ ) some time ago (between three to 15 years previously). This latter group were classified as non-counselled in later analysis.

The mean age of diagnosis for the group was 18 years (range 1 day to 49 years, SD 13 years) $(n=81)$. Fifty percent of the study group were diagnosed before the age of 14 years. The mean number of years a patient or parent had known about the diagnosis of NF1 in either themselves or in the family was 10 years (range

Table 4 Knowledge of genetic risk and inheritance of NF1.

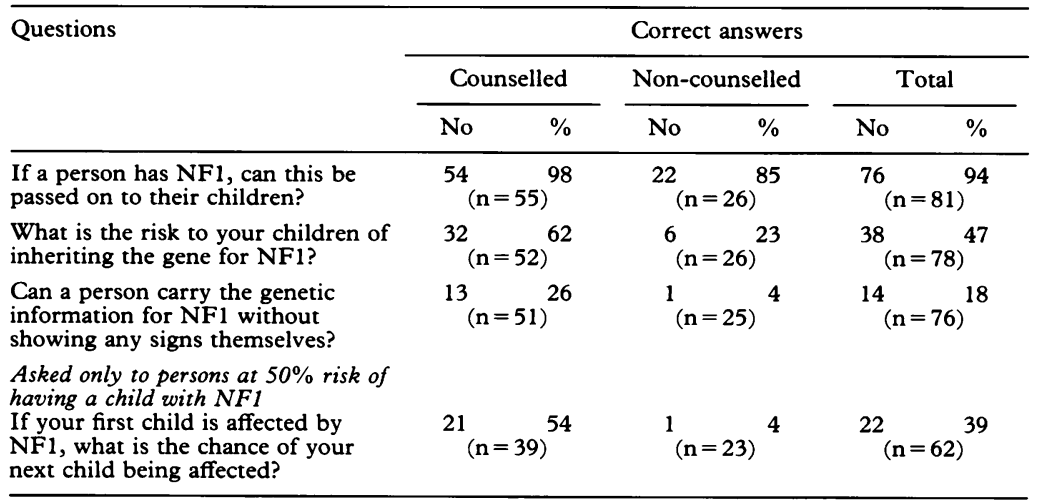

1 day to 42 years) $(n=77)$. In the interviews subjects often wished to talk about the time of diagnosis, the main themes being a lack of information given, uncertainty surrounding diagnosis, and prognosis. The majority of the diagnoses were made by hospital specialists, including clinical geneticists $(19 \%)$, paediatricians $(24 \%)$, neurologists, dermatologists and plastic surgeons (39\%), with $6 \%$ made by GPs and $11 \%$ by non-medical personnel $(n=79)$. Sixty-six subjects $(82 \%)$ stated that their child or themselves were under medical review $(n=81)$. This corresponds with the number of persons who were on the register, where annual medical review is offered. Some subjects who had been seen by the register team still felt that they were not under regular medical review. The majority indicated that they thought a special NF1 clinic would be helpful $(88 \cdot 9 \%)$.

\section{CLINICAL AND GENETIC KNOWLEDGE}

In response to direct questions, $69(85 \%)$ correctly named the condition. When asked to name some of the signs and symptoms of NF1, $72(89 \%)$ mentioned the café au lait marks or birth marks and $69(85 \%)$ mentioned the lumps on or under the skin $(n=81)$ (table 2). The other features and complications were less well known, and in many cases knowledge was restricted to their own or their family's experience of the condition. Knowledge of the variability of the clinical features was assessed by four questions; $33 \%$ knew that NF1 can vary between families $(n=81), 34 \%$ knew it could vary within a family $(n=80)$, and $67 \%$ knew that subjects may only have the cafe au lait patches $(n=79)$. However, only $17 \%$ knew that if a child did not have these by the age of 6 years, they were unlikely to have NF1 $(n=79)$. Seventy-six percent knew that additional problems associated with NF1 might develop as a patient gets older, and most subjects were able to describe one or two features $(n=81)$. The clinical geneticist was most often named as the main source of information concerning the medical aspects (table 3 ).

Four questions were asked to assess knowledge of the inheritance of NF1 and the results are shown in table 4 . The person most often named as the main source of information concerning the hereditary aspects of NF1 was again a clinical geneticist (table 3 ).

The total knowledge of each person was assessed by combining the results from the 14 medical and four genetic knowledge questions. Responses such as 'don't know' were classed as incorrect in the calculation of this score. A high knowledge score (range 14 to 18 correct answers) was obtained by eight subjects, 44 obtained a medium score (range 7 to 13 correct answers), and 29 a low score (range 0 to 6 correct answers). The mean score was 7 $(\mathrm{n}=81)$.

Factors affecting knowledge

A number of factors were analysed to see if there was any association with total knowledge 
Table 5 Factors showing significant association $(p<0.05)$ with higher total knowledge score $(n=81)$.

Genetic counselling $(p<0.0001)$ Female $(p=0.03)$

Under regular medical review $(p=0.02)$

Interest in prenatal testing $(p=0.041)$

$\begin{array}{ll}\text { Diagnosed young }(p=0.007) & \text { Higher social class }(p<0.0001) \\ \text { Worry about the neurofibromas }(p=0.031) & \text { NF1 had caused problems for the person in }\end{array}$
Table 6 Severity of NF1: patient's perception of severity $v$ medical classification.

\begin{tabular}{|c|c|c|c|c|c|}
\hline \multirow{2}{*}{$\begin{array}{l}\text { Patient's } \\
\text { perception }\end{array}$} & \multicolumn{5}{|c|}{ Medical classification } \\
\hline & Grade 1 & Grade 2 & Grade 3 & Grade 4 & Total \\
\hline $\begin{array}{c}1 \\
\text { Minimal }\end{array}$ & 8 & 3 & 0 & 0 & 11 \\
\hline & 6 & 4 & 3 & 0 & 13 \\
\hline $\begin{array}{c}3 \\
\text { Moderate }\end{array}$ & 14 & 5 & 6 & 0 & 25 \\
\hline $\begin{array}{c}4 \\
\text { Severe }\end{array}$ & 4 & 2 & 1 & 0 & 7 \\
\hline Total & 32 & 14 & 10 & 0 & 56 \\
\hline
\end{tabular}

score. Those factors showing significant association $(\mathrm{p}=<0.05)$ with a higher total knowledge score are shown in table 5 and include having had genetic counselling, higher social class, having a child with NF1, young age at diagnosis, and being a member of a patient support group. The strong association with previous genetic counselling $(p<0.001)$ was seen for both clinical and genetic knowledge.

\section{PSYCHOSOCIAL EFFECTS}

An affected patient's perception of severity

Each patient who was affected by NF1 was asked to indicate how severely they felt they were affected ( $n=56)$, by choosing between 'severely', 'moderately', 'mildly', or 'minimally'. This was then compared with the severity grade as assessed from the medical notes (see methods). Table 6 shows a comparison between the patient's perception of their own severity and the medical classification. No

Table 7 Factors showing association $(p<0.05)$ with higher perception of severity score in affected subjects $(n=56)$.

Anxiety because of the appearance of the neurofibromas $(\mathrm{p}=0.03)$

Altered dress patterns or social activities to hide the neurofibromas $(p=0.005)$

Diagnosed later in life $(p=0.02)$

Table 8 Affected subjects' experience of NF1 $(n=56)$.

\begin{tabular}{lll}
\hline School & Cosmetic aspects & Relationship \\
\hline $\begin{array}{l}\text { 63\% stated difficulty with } \\
\text { their school work }\end{array}$ & $\begin{array}{l}17 \% \text { were teased about the } \\
\text { cafe au lait marks }\end{array}$ & $\begin{array}{l}30 \% \text { felt that NF1 made } \\
\text { forming relationships more } \\
\text { difficult }\end{array}$ \\
$\begin{array}{l}\text { 27\% felt that learning } \\
\text { difficulties had an effect on } \\
\text { later achievement }\end{array}$ & $\begin{array}{l}48 \% \text { felt frightened by the } \\
\text { appearance of the } \\
\text { neurofibromas during } \\
\text { adolescence }\end{array}$ & $\begin{array}{l}39 \% \text { felt self-conscious with } \\
\text { their physical relationship } \\
\text { with their partner }\end{array}$ \\
$\begin{array}{l}\text { 13\% stated that their } \\
\text { unhappiness at school was } \\
\text { directly related to NF1 }\end{array}$ & $\begin{array}{l}44 \% \text { altered their dress } \\
\text { to hide the neurofibromas }\end{array}$ & $\begin{array}{l}29 \% \text { felt unable to talk to } \\
\text { their partner about NF1 }\end{array}$ \\
& & $\begin{array}{l}40 \% \text { felt their partner did } \\
\text { not understand how they felt } \\
\text { about NF1 }\end{array}$ \\
\hline
\end{tabular}

significant correlation between individual perception and medical classification of severity was found ( $p=0 \cdot 2441$, Kendall tau B test) with the majority perceiving themselves more severely affected (Wilcoxen signed ranks test, $\mathrm{p}<0.0001)(\mathrm{n}=56)$.

Individual perception of severity 'score'

As a patient's perception of severity did not show significant correlation with the medical classification based on clinical features, the difference between the medical classification and a patient's perception was calculated. This difference was described as a perception of severity 'score'. A positive score indicates a patient's perception as more serious, a negative score as less serious, than the medical classification. The perception of severity scores range from -1 to +3 , with a mean of $1 \cdot 21(n=56)$.

Factors showing a significant association $(\mathrm{p}=<0.05)$ with a higher perception 'score' are shown in table 7 . These included subjects who were frightened by the appearance of the lumps and also those who tried to hide them. Factors showing slight correlation included difficulty in talking to their partner about NF1 $(p=0.059)$ and those who felt self-conscious within their physical relationship $(p=0.057)$.

An affected patient's own experience of NF1

Patients mentioned problems at school, with cosmetic aspects, and within interpersonal relationships (table 8). Twenty-seven percent felt that learning difficulties encountered while at school had caused problems with later achievement, $13 \%$ stated that their unhappiness at school was directly related to their NF1, and $17 \%$ were directly teased about the café au lait marks $(n=56)$. The appearance of the neurofibromas caused fear in half of the group (many subjects were undiagnosed at this stage) and marked a change in social contacts and dress patterns. Thirty percent of subjects felt that if they did not have NF1 forming new contacts and relationships would be easier $(\mathrm{n}=55)$.

Two thirds of the group had at least one child with NF1 and $77 \%$ of the 51 parents asked said that NF1 had caused problems for their child at school. These included learning difficulties, teasing, forming friendships, and behaviour problems (table 9). Thirty-two percent of parents reported the involvement of an educational psychologist.

When the total group $(n=81)$ were asked who they would most likely turn to if they were worried about NF1 this was usually a medical professional (table 3). In an attempt to measure the extent of individual support networks, the SSQ-6 was used to assess the perceived number of support persons used in a particular situation, and also their satisfaction with this support. The group stated a mean of 2.35 persons in each area of social support and rated satisfaction with this as 5.09 out of a possible 6. Deductions from these data are limited as no control group was studied. However, the mean number of persons available for 
Table 9 Problems at school as related by parents of affected children $(n=51)$.

\begin{tabular}{llrc}
\hline & & No & Percent \\
\hline Main problem & Problems with school work & 31 & 61 \\
stated by & Forming relationships & 6 & 12 \\
parent & Behaviour problems & 2 & 4 \\
& None & 12 & 23 \\
& Total & 51 & \\
Main source of & Teacher & 14 & 27 \\
help stated by & Educational psychologist & 12 & 24 \\
parent & No sources of support & 8 & 16 \\
& Other & 4 & 8 \\
& None sought & 13 & 25 \\
& Total & 51 & \\
\hline
\end{tabular}

support or satisfaction ratings did not differ significantly between affected patients and parents of children with NF1.

THE USE OF THE PATIENT SUPPORT GROUP

Of the total study group, 59 subjects $(73 \%)$ had heard of LINK and $35(43 \%)$ stated that they were members. The majority of LINK members in this study used the organisation to obtain further information relating to the clinical features of the condition. Discussion during the interviews indicated that many who had found the written information sent to them by LINK distressing at first felt that, in retrospect, they were glad to have the facts.

REPRODUCTIVE DECISIONS

Forty-four percent of subjects who knew of the risk of NF1 before having children said that this had influenced their reproductive decisions $(n=32)$. Those subjects who reported no influence stated that this was because they knew little about the condition or because their desire for children was great. Of those who did not know about NF1 before having their children, $10(34 \%)$ stated that it would have influenced their reproductive plans if they had known $(n=29)$.

Examining the relationship between perception of severity and influence on reproductive decisions, it was found that the subject's perception of their own severity (their perception of severity 'score') or the subject's medical classification of severity did not significantly relate to those who stated that their reproductive choices had been influenced by NF1. Of the seven affected subjects who decided to limit their family, four classed themselves to be moderately affected by their NF1, two mildly, and one minimally.

The development of a prenatal test was favoured by the majority of the group $(81 \%)$ $(\mathrm{n}=81)$. Of the 29 subjects who were still considering further children, $12(41 \%)$ said they personally would be interested in having a prenatal test and of these only three would consider a termination of pregnancy. These three graded their own or their family's severity as moderate. Only one person stated that she would not consider further children unless a prenatal test was available. Some subjects who expressed a wish to know if their child was affected, but would not terminate a pregnancy, felt that as an alternative to prenatal testing, they would want the child to have a presymp- tomatic test at birth. The area of presymptomatic DNA testing in very young children is still under debate.

\section{Discussion}

This study shows that NF1 has a marked effect on the lives of affected subjects and their families. A person's perception of the severity of the condition showed no correlation with medical classification based on their clinical features. A subject's perception, as measured by this study, included the impact of nonclinical features, showing that these are also important in how a person perceives the 'burden' of NF1. The psychosocial areas of greatest concern were found to be the difficulties faced at school, and later in accepting the cosmetically disfiguring aspects of the condition. Most subjects knew that NF1 can be inherited and knowledge of basic clinical features of the condition was good. Genetic counselling and also contact with a patient support organisation resulted in a greater knowledge of both the clinical and genetic aspects of the condition. However, $77 \%$ of the non-counselled group and $38 \%$ of the counselled group were unable to identify their personal risk of having an affected child.

In this study overall knowledge of the major clinical features of NF1 was good, with $85 \%$ being able to name the diagnosis and $76 \%$ aware that NF1 could be progressive $(n=81)$. Information regarding specific complications was poor and tended to be limited to the family's own experience, or how much information they had received from the genetic counselling service or the patient support organisation.

The total knowledge scores obtained by subjects who had received genetic counselling were significantly greater than those obtained by the non-counselled group. Knowledge of the clinical features as well as the genetic aspects was good in the counselled group which shows that during the genetic counselling process information regarding the clinical features is also communicated. This is of interest in light of recent debate over the degree of involvement clinical geneticists have in the medical management of inherited conditions. ${ }^{11}$ The vast majority of subjects in both groups $(94 \%)(n=81)$ knew that NF1 could be inherited, although only $62 \%$ of the counselled group ( $n=52)$ and $23 \%$ of the non-counselled group ( $n=26)$ could correctly state the risk to future children. In the present study some parents whose child was the result of a new mutational event (both parents having been examined) still believed themselves to be at high risk of having another affected child, even after counselling. The knowledge that NF1 is a fully penetrant disorder by adulthood was poorly understood in both the counselled and non-counselled groups, as was knowledge that equal numbers of males and females are affected. This suggests a need for more careful explanation of the genetic aspects of NF1, as well as reinforcement counselling and discussion after the clinic. The above findings are in 
accordance with other recent studies of inherited conditions assessing post-counselling knowledge. ${ }^{12-15}$

Affected subjects who have a child with NF1 showed significantly greater knowledge of the condition than those without a child. Those who stated that the presence of NF1 had influenced their reproductive decisions also had a high knowledge score. Other studies have suggested that problems in reproductive decision making may encourage people to seek more information. ${ }^{1617}$ Subjects who had had problems forming relationships also had significantly higher knowledge scores. It seems that the more personal the meaning attached to the diagnosis, the more relevant the information, and hence the higher knowledge scores in these persons.

In the present study, by asking, 'How seriously do you think you have been affected by NF1?', an effort was made to obtain a subjective assessment of how the subjects felt they were clinically affected and how this had influenced their life. Responses indicated that their assessment included the psychosocial impact as well as physical manifestations of the condition. In the study, seven $(13 \%)$ subjects felt themselves to be severely affected. No significant correlation was found between the medical classification of severity and the subjects' own perception of severity. This apparent discordance has been seen in other studies measuring subjective assessment of 'burden' attached to a disorder. ${ }^{518}$ In this study this could be because of lack of knowledge about the severe complications of NF1, but also highlights the impact of the cosmetic features which may be of more relevance to the individual person and which are not taken into account by the medical classification scale. Factors other than just the clinical features of NF1 influenced how subjects felt they were affected. In the $57 \%$ (32) who graded themselves more severely affected than by the medical classification scale, there was a significant association with expression of fear about the appearance of the lumps or having attempted to hide them. The cosmetic factors do seem to play an important part in the perception of severity. The presence of a family history did not show any significant effect on perception of severity.

Subjects who were female or had a child with NF1 also showed a slightly higher perception score. This reinforces previous findings of a higher perceived 'burden' in females ${ }^{19}$ and the greater concern shown by mothers of affected children regarding the 'sociomedical' aspects of a genetic condition compared with those who are themselves affected. ${ }^{20}$

The main psychosocial effects were related to cosmetic aspects and learning difficulties early in childhood. The cosmetic aspects had caused problems for $48 \%$ of the group $(n=54)$. Teasing at school about the brown patches did not seem to be a concern but teasing because of other aspects of NF1 had caused great anxiety. These included enlarged head size, facial plexiform neurofibromas, and pseudarthrosis. Many subjects described changes in life style to try to hide the peripheral neurofibromas and restrictions in social contact. They reported concealing the lumps in order to avoid explaining the condition to other people. Young adults felt that the cosmetic features reduced their confidence in forming relationships. The appearance of the neurofibromas during the teenage years comes at a time when people are most concerned about their body image. The impact of the appearance of the peripheral neurofibromas is shown by one woman in the study (21 years old, who had a below knee amputation soon after birth for pseudarthrosis) who had an active sports life with a disabled swimming team until the peripheral neurofibromas started to develop and she then felt she could no longer face wearing her swimming costume. However, difficulties in forming relationships did not seem to affect the marriage rate, which was comparable to that in the general population. ${ }^{21}$ Twenty-nine percent of subjects who had mentioned a present or previous partner $(n=31)$ felt unable to talk to them about NF1. One affected woman mentioned that NF1 had been the cause of her separation from her husband.

Many subjects reported difficulties at school; $32 \%$ of affected persons reported being unhappy at school and tended to have a small social circle $(n=56)$ and $60 \%$ of affected persons reported difficulties with school work in junior school. One man commented "I was unable to learn quickly, to grasp new things. I was then left alone and began to get further behind". Thirty percent of affected subjects reported having played truant from school on more than one occasion. Children in school at the time of the study seem to be receiving more help with their learning difficulties than did the previous generation with $30 \%$ of children receiving help from an educational psychologist. However, problems with behaviour and teasing remain a great concern for parents.

The learning difficulties experienced at school seemed to have an effect on later confidence and achievement. One third of affected subjects felt that NF1 had restricted their career options. One subject with a few facial peripheral neurofibromas worked in a bakery and worried that if they became more obvious his job might be threatened.

If subjects were worried about NF1 they stated medical professionals as their main source of help and advice and rarely turned to family, friends, or the patient support group (LINK). Knowledge of the patient support group LINK was good. Of those aware of LINK, $61 \%$ were members. Use was mainly restricted to obtaining information about the condition and it was not often used as a support service in times of crisis or as a social network. These data were obtained before the development of Family Support worker positions funded by LINK.

From the interviews it was noted that affected subjects found forming new relationships difficult and therefore may have had restricted social support. To try to measure this the Social Support Questionnaire (SSQ-6) was used. The results from this are tentative as no 
control data were available, but both affected subjects and unaffected parents of an isolated case seemed to show few people available to offer support. In a study of subjects at risk of Huntington's disease and having an interest in predictive testing, using the full Social Support Questionnaire, the authors commented that "the individuals report a fairly extensive social support network SSQ-N=3.56". ${ }^{22}$ These data, when compared with the original study used to test the reliability of the questionnaire, where undergraduate students in psychology completed the test, produced a mean SSQ-N score of $4 \cdot 25 .^{23}$ Riccardi and Eichner ${ }^{4}$ commented that some patients with NF1 had poor social performance and this was greatest in those of lower social groups or with severe NF1 and tended to be sporadic cases. He suggested that this may be because of the overprotectiveness of parents of an affected child. No firm conclusions can be drawn from the SSQ-6 data but it does seem that further study into the social competence and interaction of subjects with NF1 is worth further investigation.

Retrospectively, NF1 had an effect on the reproductive decisions of nearly half of those who knew about NF1 before having children, but most did not refrain from having children. Couples stated that the variability of the condition was a major complicating factor in decision making. The relevant recurrence risk to the family incorporates the extent to which a child may be affected, as well as the genetic risk, as noted in other studies of inherited conditions. ${ }^{24} 25$

Although just under half of those considering a future pregnancy expressed an interest in prenatal diagnosis, most indicated they would not terminate an affected pregnancy. This reflects the low uptake of prenatal diagnosis for NF1 reported in a recent study from Wales. ${ }^{26}$ This probably reflects the great variability in prognosis, and has been seen in other late onset variable conditions. ${ }^{27} 28$

The perceived burden of the condition has been linked with reproductive decisions in some studies. ${ }^{2930}$ In the present study the three subjects wishing to have a prenatal test with termination of an affected child rated the condition in the family as moderate and had personal or family experience of one or more complications of NF1. Some subjects in the study found decision making particularly difficult and expressed fears of being unable to cope with the guilt if the child was affected. Lippmann-Hand and Fraser ${ }^{31}$ found that couples use both the factual information given in counselling and the experiences available to them to determine if they could manage the consequences of taking the risk. ${ }^{31}$ With NF1 this is very difficult as personal experience of the condition often does not give a representative picture of the condition.

Previous studies have described the social and psychological impact of genetic conditions on families. ${ }^{1532-34}$ The present study shows the varied psychosocial effects of NF1. Further study is needed to assess the issues raised relating to the uncertain prognosis, the dis- figuring aspects of the condition, and the apparent reduced social interaction of affected persons. Future research to define the impact of other genetic conditions will enable professionals to offer more effective information and supportive counselling to families with genetic disease.

1 Huson SM, Compston DAS, Harper PS. A study of von Recklinghausen neurofibromatosis in south east Wales. II. Guidelines for genetic counselling. $f$ Med Genet 1989;26:712-21.

2 Huson SM, Compston DAS, Clark P, Harper PS. A study of von Recklinghausen neurofibromatosis in south east Wales. I. Prevalence, fitness, mutation rate, and effect of parental transmission on severity. $f$ Med Genet parental transmis

3 Huson SM, Harper PS, Compston DAS. Von Recklinghausen NF. A clinical and population study in south east sen NF. A clinical and popula
Wales. Brain 1988;111:1355-81.

4 Riccardi VM, Eichner JE. Neurofibromatosis: phenotype, natural history, and pathogenesis. Baltimore: Johns Hopkins University Press, 1986:150-62.

5 Samuelsson B. Neurofibromatosis (von Recklinghausens disease): a clinical, psychiatric and genetic study. MD Thesis, University of Gothenburg, Sweden, 1981.

6 Rubenstein A, Korf B. Neurofibromatosis-a handbook for patients, families and health-care professionals. New York: Thieme Medical Publishers, 1990.

7 Cawthon RM, Weiss R, Gangfeng $\mathrm{X}$, et al. A major segment of the NFI gene: cDNA sequence, genomic structure and point mutations. Cell 1990;62:193-201.

8 Wallace M, Marchuk DA, Andersen LB, et al. Type 1 neurofibromatosis gene: identification of a large transcript neurofibromatosis gene: identification of a large transcript

9 Riccardi VM, Eichner JE. Neurofibromatosis: phenotype, natural history, and pathogenesis. Baltimore: Johns Hopkins University Press, 1986:37-56.

10 Sarason IG, Sarason BR, Shearin EN, Pierce GR. A brief measure of social support: practical and theoretical implications. F Soc Pers Rel 1987;4:497-510.

11 Clarke A. Is non directive genetic counselling possible? Lancet 1991;338:998-1001.

12 Evers-Kiebooms G. Decision making in Huntington's disease and cystic fibrosis. In: Evers-Kiebooms G, Cassiman $\mathrm{JJ}$, van den Berghe H, D'Yobwalle G, eds. Genetic risk, risk perception and decision making. Birth Defects 1987;23(2):115-49.

13 Curtis D, Johnson M, Blank CE. An evaluation of reinforcement of genetic counselling on the consultand. $A m \mathcal{F}$ Med Genet 1988;33:270-6.

14 Denayer L, Evers-Kiebooms G, van den Berghe H. A child with CF. I. Parental knowledge about the genetic transmission of CF and about DNA-diagnostic procedures mission of CF and about D

15 Weil J. Mothers postcounselling beliefs about the causes of their children's genetic disorders. Am $\mathcal{F}$ Med Genet 1990;48:145-53.

16 Hodgkinson K, Kerzin-Storrar L, Watters A, Harris R. Adult polycystic kidney disease: knowledge, experience, and attitudes to prenatal diagnosis. $\mathcal{f}$ Med Genet 1990;27:552-8

17 Fretz PG, Duivenvoorden HJ, Verhage F, Peters-Romeyn BMT, Niermeijer MF. Analysis of problems in making the reproductive decision after genetic counselling. $\mathcal{F}$ Med Genet 1991;28:194-200.

18 Pearn JH. Patients' subjective interpretation of risks offered in genetic counselling. $\mathcal{f}$ Med Genet 1973;10:129-34

19 Somer M, Mustonen H, Norio R. Evaluation of genetic counselling: recall of information, post counselling reproduction and attitude of the counsellees. Clin Genet 1988;34:352-65.

20 Sorenson JR, Swazey JR, Scotch NA. Reproductive pasts, reproductive futures, genetic counselling and it's effectiveness. Birth Defects 1981;17(4):51-79.

21 Office of Population Census and Surveys. Key population and vital statistics. London: HMSO, 1981.

22 Bloch M, Fahy M, Fox S, Hayden MR. Predictive testing for Huntington disease. II. Demographic characteristics, life style patterns, attitudes and psychosocial assessments of the first 51 test candidates Am 7 Med Genet 1989;32:217-24.

23 Sarason IG, Levine HM, Basham RB, Sarason BR. Assessing social support: the social support questionnaire. $\mathcal{F}$ Pers Soc Psychol 1983;44:127-39.

24 Emery AEH, Raeburn J, Skinner R, Holloway S, Lewis E Prospective study of genetic counselling. BMF i: $1253-6$.

25 Frets PG, Duivenvoorden HJ, Verhage F, Niermeijier MF van den Berge SMM, Galjaard $H$. Factors influencing the reproductive decision after genetic counselling. $A m \mathcal{J}$ Hum Genet 1990;35:503-9.

26 Upadhyaya M, Fryer A, MacMillan J, Broadhead W, Huson SM, Harper PS. Prenatal diagnosis and presymptomatic detection of neurofibromatosis type $1 . \mathcal{J} \mathrm{Med}$ Genet 1992;29:180-3.

27 Kerzin-Storrar L, Kahn AA, Watters AE, et al. A regional genetic family register: opportunity for active rather than reactive genetic counselling. Am $\mathcal{f}$ Hum Genet 1992;49:3 28 Van Spijker H, Ten Hove H, Ippel PF. Follow-up of 
genetic counselling in autosomal neurological disorders. $f$ Genet Counsel (in press).

29 Shaw MW. Review of studies of genetic counselling: a critique. In Lubs HA, de la Cruz F, eds. Genetic counselling. New York: Raven Press, 1977:35-52.

30 Evers-Kiebooms G, van den Berghe H. Impact of genetic counselling: a review of published follow up studies. Clin
Genet 1979;15:465-74.

31 Lipper 1979,15:465-74.

poser CF. Genetic counselling-the postcounselling period. II Making reproductive choices. Am $\mathcal{F}$ Med Genet 1979;4:73-87.
32 Firth MA. Diagnosis of Duchenne muscular dystrophy: experiences of parents of sufferers. BMF 1983;286:700-1. 33 Tyler A, Harper PS. Attitudes of subjects at risk and their relatives towards genetic counselling in Huntington's relatives towards genetic counselling
chorea. $\mathcal{F}$ Med Genet 1983;20:179-88.

34 Evers-Kiebooms G, Swerts A, Cassiman JJ, van den Berghe E. The motivation of at risk individuals and their partners in deciding for or against predictive testing for Huntington's disease. Clin Genet 1989;35:29-40. 